\title{
GESTÃO ESCOLAR: UM ESTUDO DO PROCESSO DE IMPLANTAÇÃO DO PROJETO “ESCOLA SEGURA E CIDADÃ- PESC” NA ESCOLA ESTADUAL DE TEMPO INTEGRAL MARIA DO CÉU VAZ D'OLIVEIRA-MANAUS-AM, BRASIL ${ }^{1}$
}

\author{
SCHOOL MANAGEMENT: A STUDY OF THE PROJECT IMPLEMENTATION OF THE \\ PROJECT "ESCOLA SAFE AND CITIZEN-PESC" AT THE STATE SCHOOL OF INTEGRAL \\ TIME MARIA DO CÉU VAZ D'OLIVEIRA-MANAUS-AM, BRAZIL
}

GESTIÓN ESCOLAR: ESTUDIO DEL PROYECTO EJECUCIÓN DEL PROYECTO "ESCOLA SEGURA Y CIUDADANA-PESC" EN LA ESCUELA ESTATAL DE TIEMPO COMPLETO MARIA DO CÉU VAZ D'OLIVEIRA-MANAUS-AM, BRASIL

\begin{abstract}
Rute Costa Lima
Secretaria Estadual de Educação e Desporto do Estado do Amazonas, Manaus, AM, Brasil. E-mail: rutlima10@hotmail.com
\end{abstract}

DOI: https://doi.org/10.46550/amormundi.v2i6.131

Trabalho Científico Decorrente da Pesquisa de Mestrado

\begin{abstract}
Resumo: As dificuldades encontradas nas salas de aulas pelos docentes relacionadas ao comportamento dos alunos são caracterizadas nos dias atuais como uma grande barreira para a construção do conhecimento. Essa barreira, classificada muitas vezes como intransponível, dado o elevado índice de indisciplina apresentado nas escolas brasileiras, foi o que motivou o desenvolvimento da pesquisa de mestrado intitulada "Gestão Escolar: um estudo do processo de implantação do Projeto Escola Segura e Cidadã na Escola Estadual de Tempo Integral Maria do Céu Vaz D’Oliveira- Manaus-AM, Brasil, haja vista, notadamente o perfil dos jovens estudantes contemporâneos esteja marcado por atitudes de desrespeito e que, em situaçôes excepcionais podem culminar para a violência física. Problemática acentuada quando este público se depara com Professores com pouco ou sem nenhum domínio de classe ou quando há omissão pela escola. Partindo dessa premissa, entende-se que a escola ao cumprir seu papel no que concerne à oferta de educação de qualidade, deve desenvolver estratégias que visem minimizar tal inquietude. Esta pesquisa estudou todo o desenho do processo de implantação em uma Escola de Tempo Integral de um Projeto de cunho disciplinar com escopo desenvolvido pela Polícia Militar do Estado do Amazonas e utilizado como ferramenta pedagógica. Dessa forma, foi possível identificar, a partir de observações sistemáticas, as ações dos discentes antes e após a implantação do projeto, concomitantemente mapear os conflitos, tensōes, resistências e expectativas abrolhadas no decorrer do estudo. Os resultados obtidos a partir da tabulação de dados e entrevistas realizadas vislumbraram mudança significativa no comportamento individual dos discentes, o que concorreu para maior rendimento pedagógico, atrelado resgate do entusiasmo docente, mas também sugere-se alguns ajustes no escopo do Projeto, a fim de subsidiar uma proposta mais eficiente.
\end{abstract}

Palavras-chave: Indisciplina. Comportamento. Mudança.

1 Pesquisa apresentada ao Programa de Pesquisa e Pós-Graduação da Universidad de Desarollo Sustentable - UDS. Mestrado em Ciências da Educação. Ârea de concentração: Educação. Cons. Ley Creacion no 3.334/07-Assunção-PY. Orientadora: Profo Dr. Leopoldo Briones Salazar

Período: 08/01/2018 a 10/01/2020 


\begin{abstract}
The difficulties encountered in classrooms by teachers related to the behavior of students are currently characterized as a major barrier to the construction of knowledge. This barrier, often classified as insurmountable, given the high level of indiscipline in Brazilian schools, was what motivated the development of the master's research entitled "School Management: a study of the implementation process of the Safe and Citizen School Project at the State School of Integral Time Maria do Céu Vaz D'Oliveira-Manaus-AM, Brazil, in particular, the profile of contemporary young students is marked by disrespectful attitudes that, in exceptional situations, can culminate in physical violence. An accentuated problem when this audience is faced with Teachers with little or no class control or when there is omission by the school. Based on this premise, it is understood that the school, when fulfilling its role in terms of providing quality education, must develop strategies that aim to minimize such concern. This research studied the entire design of the implementation process in Integral-Time School of a disciplinary project with a scope developed by the Military Police of the State of Amazonas and used as a pedagogical tool. In this way, it was possible to identify, from systematic observations, the actions of students before and after the implementation of the project, concomitantly mapping conflicts, tensions, resistances and expectations that developed during the study. The results obtained from the tabulation of data and interviews carried out glimpsed a significant change in the individual behavior of students, which contributed to greater pedagogical performance, linked to the rescue of teaching enthusiasm, but some adjustments in the scope of the Project are also suggested, in order to subsidize a more efficient proposal.
\end{abstract}

Keywords: Indiscipline. Behavior. Change.

Resumen: Las dificultades que encuentran los docentes en las aulas relacionadas con la conducta de los estudiantes se caracterizan actualmente como una gran barrera para la construcción del conocimiento. Esta barrera, muchas veces calificada como insuperable, dado el alto nivel de indisciplina en las escuelas brasileñas, fue lo que motivó el desarrollo de la investigación de maestría titulada "Gestión escolar: un estudio del proceso de implementación del Proyecto Escuela Segura y Ciudadana en la Escuela Estatal de Tiempo Completo Maria do Céu Vaz D'Oliveira-Manaus-AM, Brasil, en particular, el perfil de los jóvenes estudiantes contemporáneos está marcado por actitudes irrespetuosas que, en situaciones excepcionales, pueden culminar en violencia física. Un problema acentuado cuando este público se enfrenta a Profesores con poco o ningún control de clase o cuando hay omisión por parte de la escuela. Con base en esta premisa, se entiende que la escuela, al cumplir con su rol de brindar una educación de calidad, debe desarrollar estrategias que tengan como objetivo minimizar dicha preocupación. Esta investigación estudió todo el diseño del proceso de implementación en una Escuela de Tiempo Completo de un proyecto disciplinar con un alcance desarrollado por la Policía Militar del Estado de Amazonas y utilizado como herramienta pedagógica. De esta forma, fue posible identificar, a partir de observaciones sistemáticas, las acciones de los estudiantes antes y después de la implementación del proyecto, mapeando concomitantemente los conflictos, tensiones, resistencias y expectativas que se desarrollaron durante el estudio. Los resultados obtenidos de la tabulación de datos y entrevistas realizadas vislumbraron un cambio significativo en el comportamiento individual de los estudiantes, lo que contribuyó a un mayor desempeño pedagógico, ligado al rescate del entusiasmo docente, pero también se sugieren algunos ajustes en el alcance del Proyecto, con el fin de subsidiar una propuesta más eficiente.

Palabras clave: Indisciplina. Comportamiento. Cambio.

\title{
1 Introdução
}

tema abordado nesta pesquisa configura-se como uma das maiores inquietaçóes vividas nos ambientes escolares do Brasil, sejam eles públicos ou privados. $\mathrm{O}$ Significativo aumento nos índices de violência nas escolas brasileiras está diretamente relacionado à indisciplina. Garcia (1999), pondera que a indisciplina contemporânea apresenta nova expressão, tendo assim, maior complexidade de resolução. 
A indisciplina escolar, tida como um problema pretérito e crescente, têm contribuído à redução expressiva da busca pela profissão docente, bem como a mudança de carreira de profissionais já inseridos no mercado de trabalho, causado muitas vezes pela necessidade financeira de exposição à longas jornadas laborais e consequente adoecimento. Não menos importante que o desgaste emocional dos docentes é a queda dos índices de aprendizagem apresentados nos últimos anos pelas avaliaçóes em larga escala.

Transformar essa realidade e estabelecer os padróes necessários a um ambiente saudável no qual a construçáo do conhecimento se conceba de forma profícua, é o que se espera da escola ao exercer seu papel social. Entretanto, melhorar o padráo comportamental de alunos de diferentes perfis que carregam em suas bagagens os mais variados desarranjos sociais, frente a um problema defendido por Parrat-Dayan, 2008, como mundial, é necessário um olhar holístico, visando uma percepção abrangente dos aspectos sociais, culturais e emocionais que envolvem seus atores.

A Gestão escolar apresenta papel estratégico nesta organização, haja vista dispor dos mecanismos fundamentais que possam sugerir alternativas pedagógicas que visem alcançar mudanças dentro dessa perspectiva.

Partindo dessa premissa, se esquadrinhou estudar todo o processo de implantaçáo do Projeto Escola Segura e Cidadã-PESC, na Escola Estadual de Tempo Integral Maria do Céu Vaz D’Oliveira- Manaus-AM, sendo realizadas observações diretas e sistemáticas das açóes praticadas pelos alunos antes e após a implantaçáo do projeto, sendo o registro feito em grade fechada.

A metodologia utilizada para desenvolver a pesquisa foi pesquisa-ação com abordagem qualiquantitativa, com coleta de dados a partir de entrevistas estruturadas, registros fotográficos e dados coletados a partir de observações diretas e sistemáticas. À luz das observaçôes diretas e sistemáticas foi possível identificar varáveis que também ocuparam lugar de destaque no contexto da pesquisa, o que possibilitou a promoçáo de açóes de caráter continuo.

\section{Revisão da literatura}

O tema da pesquisa, por ser amplamente discutido, permitiu o suporte necessário, além de garantir uma larga visão na problemática que permeia as escolas brasileiras. $\mathrm{O}$ marco inicial baseou-se na trajetória histórica da educação no Brasil, com aporte de Luzuriaga (1983) e Giles (1987), os quais afirmam que historicamente a educação se caracterizava pela continuidade dos valores morais e sociais.

O contexto histórico foi imprescindível para o vislumbre do atual quadro da educação, porquanto contemporaneamente observa-se o declínio destes valores nas unidades de ensino, sobrepondo-se a extrema fragilidade de seus atores frente a omissão de políticas públicas eficientes e escolas sucateadas, assim como o aumento de professores adoecidos como a Síndrome da Desistência, mencionada por Codo e Menezes (1999) como Burnout.

Associado ao desestimulo em detrimento à extrema desvalorização financeira, o quadro é agravado pelo perfil do "estudante de hoje", que se apresenta sem qualquer limite de disciplina. Nesse contexto Parrat-Dayan (2008), assegura que a indisciplina não é um fenômeno estático, La Taille (2004), por sua vez pondera sobre a incapacidade dos alunos em se ajustar às normas estabelecidas. 
Partindo dessa premissa, buscamos refletir e ponderar acerca das conjunturas sociais, culturais e emocionais, ora atreladas ao comportamento dos alunos no ambiente escolar.

$\mathrm{Na}$ pesquisa de campo acenamos com Chalita (2001), quando afirma que a responsabilidade de educar é de toda sociedade a começar pela família. A parceria entre família e escola apresenta-se como um elo às respostas dos conflitos individuais exibidos no ambiente escolar, Parolim (2007), afirma que família precisa da escola, pois ela sozinha não dá conta da educação e socialização dos filhos. Winnicott (1982), afirma que "existe um processo duplo entre o lar e a escola: as tensóes que são geradas num ambiente manifestam-se como perturbaçóes no comportamento do outro".

Ademais, rico arcabouço literário internacional enriqueceu e permitiu a percepção holística e consequente construçáo do pensamento crítico sobre o tema abordado.

\section{Objetivo geral}

O Objetivo geral da pesquisa buscou analisar minunciosamente todo o processo de implantação do Projeto "Escola Segura e Cidadã (PESC)" na Escola Estadual de Tempo Integral Maria do Céu Vaz D’Oliveira-Manaus-AM, Brasil.

\section{Objetivos específicos}

- Conhecer os fundamentos do Projeto "Escola Segura e Cidadã (PESC)";

- Descrever o diagnóstico da situação da violência e indisciplina na escola;

- Identificar as atividades desenvolvidas no processo de implantação do Projeto;

- Caracterizar as mudanças nas práticas dos professores e alunos na implantação do Projeto;

- Identificar as contribuiçóes e resultados da implantação do Projeto;

determinar as tensões e conflitos existentes na implantação do Projeto.

\section{Metodologia}

A metodologia utilizada para a realização do trabalho dividiu-se em três etapas, sendo a primeira exploratória, pela construção de base epistemológica, objetivando conhecer e os elementos de cunho físico e documental necessários ao desenvolvimento da pesquisa.

A segunda etapa se deu com a pesquisa de campo, cujo caráter foi de pesquisa-ação com abordagem qualiquantitativa, com a coleta de dados construída a partir de observaçóes diretas e sistemáticas em grade fechada, da qual fizeram parte 195 alunos, além das entrevistas estruturadas realizadas com 09 participantes, totalizando 204 sujeitos envolvidos.

As entrevistas, segundo Del-Masso; Cotta e Santos (2018), permite aprofundar o conhecimento para fazer uma interpretação mediante a análise de conteúdo, o que subsidiou grandemente a terceira etapa, pertinente à construção dos dados expostos através de gráficos e posterior análise. A revisão bibliográfica em seus aportes nacionais e internacionais embasaram de forma profícua todas as etapas da pesquisa. 


\section{Resultados}

A proposta de estudar a implantação do Projeto "Escola Segura e Cidadã-PESC", criado pela Polícia Militar do Estado do Amazonas e indicado às Escolas Públicas do Estado, nos possibilitou identificar as contribuiçôes trazidas à Escola Estadual de Tempo Integral Maria do Céu Vaz D’Oliveira, assim como os ajustes necessários ao escopo do projeto, como forma de garantir maior eficácia como instrumento pedagógico disciplinar.

Após dez meses, período de duração da pesquisa, com a tabulação dos dados, observamos que o projeto, cuja base é alicerçada sobre a meritocracia, apresentou, quanto à sua práxis, excelentes resultados. A mudança comportamental dos alunos fora refletida no processo ensinoaprendizagem, comprovado pelos dados apresentados no último bimestre. A queda significativa nos parâmetros analisados como xingamento, atos violentos, desrespeito aos colegas e professores, palavras de baixo caláo, destruição do patrimônio público, entre outros, confirmou a eficácia do projeto, corroborado pelo aumento do rendimento pedagógico.

\section{Consideraçóes finais}

Elencamos dois parâmetros de grande relevância, haja vista termos identificado: resistência de alguns alunos à uma nova cultura no ambiente escolar e em outros, o afloramento da auto estima ao vislumbrarem da oportunidade de fazer parte de um novo ambiente que se constituía pela reconhecimento meritocrático. Dentro desse contexto, recortes de circunstâncias, ocorrências e posiçôes atingidas em decorrência da nova rotina, necessitaram maior atenção, uma vez que o novo escopo da escola fora estabelecido por açóes de caráter continuo. Dessa forma, corroborou-se o papel fundamental desempenhando por uma gestáo comprometida, no que diz respeito à proposição e condução de novas práticas e mediação de forma competente dos conflitos e tensôes observados no início da implantação do projeto,

\section{Conclusóes}

Ao final deste estudo, podemos concluir que o PESC, enquanto ferramenta pedagógica disciplinar, trouxe resultados significativos a escola, haja vista ter possibilitado a construção de uma nova cultura, trazendo dessa forma um ressignificado para o ambiente escolar e por conseguinte, familiar.

Entretanto, é necessário rever o escopo do projeto, haja vista não se observar uma figura que, ao término da implantação conduza a continuidade das ações previstas, assim como um treinamento especifico, já que ao lidar com crianças e adolescentes, um olhar de respeito frente os diversos conflitos pessoais devem ser precursor nas relaçóes interpessoais do ambiente escolar, Dessa forma, a manutenção diária dos valores construídos garantirá o sucesso do projeto.

\section{Referências}

CARNEIRO, Neri de Paula. Educaçáo dos primórdios aos dias atuais. Disponível em: https:/www.webartigos.com/artigos/educacao-dos-primordios-aos-nossos-dias/16606. Acesso em: 03 nov. 2018. 
CHALITA, Gabriel. Educação: a solução está no afeto. São Paulo: Gente, 2001.

CODO, Wanderley; MENEZES, Iône V. O que é Burnout? In: CODO, Wanderley. (Coord.). Educaçáo: carinho e trabalho: Burnout a síndrome da desistência do educador que pode levar à falência da educação. Petrópolis: Vozes, 1999. p. 237-254.

DEL-MASSO, Maria Candida Soares; COTTA, Maria Amélia de Castro; SANTOS, Marisa Aparecida Pereira.Ética em Pesquisa Científica: conceitos e finalidades. Disponível em:https:// acervodigital.unesp.br/bitstream/unesp/155306/1/unesp-neadreei1 eid04texto2.pdf. Acesso em: 15. junho.2018.

GARCIA, Joe. Indisciplina na escola: uma reflexão sobre a dimensão preventiva. Revista Paranaense de Desenvolvimento, Curitiba. n.95, p.101-108, 1999.

GILES, T. Ransom. História da educação. São Paulo: E.P.U. 1987

LA TAILLE, Yves. Limites: três dimensôes educacionais. São Paulo, SP: Ática, 2004.

LUZURIAGA, L. História da educação e da pedagógica. 19. ed. São Paulo: Nacional. 2001.

PARRAT-DAYAN, Silvia. Como enfrentar a indisciplina na escola. Trad. Silvia Beatriz Adoue e Augusto Juncal -São Paulo: Contexto, 2008.

PAROLIN, Isabel Cristina Hierro. Pais e educadores: quem tem tempo de educar? Porto Alegre: Mediação, 2007.

WINNICOTT, D. W. A criança e o seu mundo. 6. ed. Rio de Janeiro: LTC, 1982. 